\title{
UM OLHAR HISTÓRICO SOBRE A EMERGÊNCIA DOS PRIMEIROS CLUBES ESPORTIVOS NA CIDADE DE TEUTÔNIA, NO RIO GRANDE DO SUL
}

\author{
Cecília Elisa Kilpp \\ Universidade Federal do Rio Grande do Sul, Porto Alegre, Rio Grande do Sul, \\ Brasil
}

\section{Janice Zarpellon Mazo}

Universidade Federal do Rio Grande do Sul, Porto Alegre, Rio Grande do Sul, Brasil

\section{Vanessa Bellani Lyra}

Universidade Federal do Rio Grande do Sul, Porto Alegre, Rio Grande do Sul, Brasil

\section{Resumo}

Este estudo objetivou identificar como foram organizadas as primeiras associações esportivas na cidade de Teutônia no Rio Grande do Sul. Para tanto, foram utilizados documentos históricos sobre os clubes. Um contexto belicoso possibilitou que um grupo de imigrantes alemães criasse o primeiro clube esportivo para a prática do tiro ao alvo e, desde então, outras práticas tradicionais foram introduzidas nas associações: bolão, ginástica, atletismo e ciclismo. Passadas as guerras territoriais, os clubes mantiveram os costumes alemães, mas, com a Segunda Guerra Mundial e o Estado Novo no Brasil, houve a perseguição aos imigrantes alemães, o que repercutiu nos clubes com o enfraquecimento dos esportes tradicionais alemães e a inclusão de outras práticas como futebol, voleibol e basquetebol.

Palavras-chave: Clubes - História do Esporte - Identidades Étnicas

\section{Introdução}

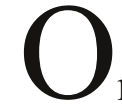

presente estudo aborda a construção do associativismo esportivo na cidade de Teutônia, localizada no Estado do Rio Grande do Sul. Colonizada por imigrantes alemães, no século XIX, a referida cidade preserva, até os dias atuais, algumas práticas esportivas herdadas da cultura germânica. Assim, para além da prática de esportes, os clubes esportivos emergiam como espaço privilegiado de celebração dos costumes alemães.

$\mathrm{O}$ associativismo esportivo engloba clubes, sociedades, agremiações, ligas, toda forma de organização esportiva. Além disso, segundo Mazo (2004, p. 24), uma associação esportiva compreende um "amplo 
repertório de símbolos, valores, normas, comportamentos e outras formas de representações, e neste sentido pode ser visto como um mecanismo de afirmação da identidade cultural teuto-brasileira". Por meio dos clubes esportivos, possibilitou-se, aos imigrantes alemães, a preservação de sua identidade étnica e cultural, pela manutenção de suas tradições e seus costumes. Os clubes e sociedades são apontados em diversos estudos (LANDO; BARROS, 1980; SILVA, 2006; MAZO, 2004) como um espaço de sociabilidade, de formação de lideranças, um lugar para o estabelecimento de contatos comerciais e, ainda, como um espaço para a prática do germanismo ${ }^{1}$.

Diante do exposto, este estudo buscou identificar como ocorreu a organização dos primeiros clubes esportivos em Teutônia, no final do século XIX e princípio do século XX, com apoio teórico-metodológico em autores da História Cultural (PESAVENTO, 2004; BURKE, 2005), que partem do pressuposto de que a realidade social é culturalmente construída.

No que tange à sua relevância, esta pesquisa ${ }^{2}$ é justificada na medida em que contribui para a construção e divulgação da maneira que se constituiu o fenômeno do associativismo esportivo no Rio Grande do Sul.

\section{DEUTSCHLAND-IMMIGRATION UND DIE KOLONIE TEU- TONIA: imigração alemã e a colônia Teutônia}

Em princípios do século XIX, o Brasil não oferecia oportunidades aos imigrantes alemães, pois já possuía mão de obra servil. Porém, o governo brasileiro teve a iniciativa de ocupar e povoar zonas até então desocupadas e distantes, a fim de "ampliar o fornecimento de recursos materiais e humanos aos exércitos imperiais, quando as intrigas com os vizinhos platinos adquirissem maior intensidade" (MOURE, 1980, p. 93).

A colonização estrangeira, quando foi introduzida no Rio Grande

1-A palavra "germanismo", do alemão deutschtum, se refere à ideologia difundida entre os teuto-brasileiros, destinada a preservar sua identidade étnica, sua cultura, sua língua, a lealdade ao país de origem. Esta ideologia estava representada em quase todas as organizações culturais e esportivas (GERTZ, 1980, p. 207).

2-Esta pesquisa é o desdobramento de um projeto mais amplo denominado "Memórias do Esporte e da Educação Física no Rio Grande do Sul: estudos históricos”, coordenado pela Profa. Dra. Janice Zarpellon Mazo. 
do Sul, não resultou de fatores históricos espontâneos, mas de uma política agrária direcionada para o estabelecimento da pequena propriedade rural a fim de ocupar e proteger as terras reais das possíveis incursões de espanhóis nas regiões desertas do Rio Grande do Sul devido ao limite político ainda não estabelecido.

A fronteira meridional do Brasil sofreu oscilações no território atual do Rio Grande do Sul, cujos limites somente se estabeleceram quando os alemães começaram a imigrar, em 1824, para a Real feitoria do Linho Cânhamo, localizada em São Leopoldo. O Estado, reduzido à Serra do Sudeste, à Depressão Central e aos degraus superiores do Planalto Setentrional, sofreu ataques e se tornou palco de violentas guerras territoriais (ROCHE, 1969).

Nesse período belicoso, a colonização alemã foi crescendo rapidamente e a população de São Leopoldo também aumentou. De acordo com Lang (1995), os descendentes teuto-brasileiros ${ }^{3}$ da Colônia de São Leopoldo, e de outras colônias antigas, fizeram emergir a necessidade de ampliação da área inicial da colônia, a partir de 1853, mesmo com as investidas militares. Dentre as novas colônias, foi criada a de Estrela e Teutônia.

A Colônia Estrela foi então fundada em 20 de maio de 1856 por imigrantes alemães oriundos da região do Hunzrück na Alemanha. A Colônia Teutônia, por sua vez, foi fundada em 1858, também por teuto-brasileiros e, posteriormente, pelos westfalianos ${ }^{4}$ vindos do Rio de Janeiro em 20 de agosto de 1868. Ambas faziam parte do município de Taquari até 1876 (LANG, 1995).

A Lei Provincial no 1.044, de 20 de maio de 1876, criou o município de Estrela, compreendendo a área dos atuais municípios de Estrela, Lajeado, Encantado, Muçum, Guaporé, Teutônia, Westfália e Imigrante. Em 1886, outra Lei Provincial, no 160, cria o novo município de Estrela, passando a compreender Estrela e Teutônia (LANG, 1995).

De acordo com Lang (1995), foram os westfalianos que se destacaram pela constituição de associações culturais, recreativas, esportivas e religiosas na região interiorana das colônias. A instalação deste gru-

3-A denominação "teuto-brasileiros" corresponde aos filhos de alemães, nascidos no Brasil.

4-Os westfalianos são alemães oriundos de Westfália, região da Renânia, localizada no norte da Alemanha próxima à Holanda. 
po em áreas acidentadas das encostas dos morros favoreceu a formação de um grupo homogêneo e o isolamento geográfico tornou possível a manutenção dos costumes e hábitos deste grupo: seus descendentes continuaram mantendo elementos da cultura dos antepassados; tornou-se possível a manutenção do dialeto Plattdüütsch'; houve a preocupação com a formação dos filhos e as entidades comunitárias foram priorizadas (LANG, 1998).

\section{SPORTS VEREIN UND IHR SPORTPRAXIS: associações esportivas e suas práticas}

O período em que o associativismo germânico se concentrou em terras sul-rio-grandenses compreendeu os anos de 1850 a 1942, período este marcado pela ascensão econômica dos comerciantes e pela atuação dos brummers ${ }^{6}$ que ascenderam o germanismo nos teuto-brasileiros por meio das associações, ou seja, as associações eram fechadas, onde somente alemães e seus descendentes eram aceitos como sócios, a língua falada era a alemã e os valores praticados os germânicos (FLORES, 2004). Além destas manifestações, havia comemorações de datas cívicas relacionadas à sua pátria de origem que homenageavam personalidades como Wilhelm $\mathrm{II}^{7}$, Otto von Bismarck $^{8}$ e Friedrisch Ludwig Jahn ${ }^{9}$.

As práticas esportivas, nos clubes alemães, estavam subordinadas

5-O dialeto Plattdüütsch imigrou ao Brasil junto com os alemães da Westfália e faz parte da língua saxônica, sendo semelhante à língua holandesa. Por este motivo, os demais alemães que aqui estavam não entendiam muito bem o dialeto, que ficou conhecido como "sapato-de-pau" - calçado utilizado e trazido junto por esta população devido ao frio em sua terra natal (http://www.westfalia.rs.gov.br/municipio/cultura_lazer.html).

6-Brummers foram os mercenários contratados pelo governo. O nome refere-se a "resmungão", pois reclamavam que o pagamento não ouro ou prata, como prometido (OLIVEIRA, 1987).

7-Wilhelm II foi o último imperador alemão e último rei da Prússia entre 1888 a 1918 (http://pt.wikipedia.org/wiki/Wilhelm_II).

8-Otto von Bismarck foi símbolo da unificação alemã quando se tornou primeiroministro da Prússia (1862-1890). No ano de 1871 a 1890, ficou conhecido como "chanceler de ferro" no cargo de primeiro chanceler do Império Alemão (http://pt.wikipedia.org/wiki/Otto_von_Bismarck ).

9-Friedrich Ludwig Christoph Jahn foi o criador do Método Ginástico Alemão e, por isso, considerado o "Pai da Ginástica" (TESCHE, 1996). 
ao local de fundação da associação. As sociedades de ginástica foram criadas nos centros comerciais das colônias, como, por exemplo, em Estrela, pois estes eram locais onde ocorria maior circulação de pessoas de outras cidades e países, trazendo destes locais novos conhecimentos e novas práticas esportivas. Além disso, as cidades com maior ascensão econômica possuíam um porto, pois a navegação era fundamental, na época, para o transporte e o comércio de grande porte. $\mathrm{O}$ crescimento econômico possibilitou que os filhos dos grandes comerciantes fossem estudar na Europa e, quando retornavam, traziam consigo o conhecimento de novas práticas esportivas.

Nas colônias interioranas, como em Teutônia, as práticas esportivas eram diferentes das que ocorreram nos centros urbanos. $\mathrm{O}$ tiro ao alvo, o bolão, a bocha, por exemplo, eram esportes mais comuns e mais acessíveis para serem introduzidos nas pequenas colônias. As práticas esportivas introduzidas se desenvolveram no período em que as colônias tinham atingido certo estágio de crescimento e por intermédio de fornecedores dos estabelecimentos comerciais (armazéns) que traziam consigo, por onde passavam, alguma novidade.

A primeira associação esportiva do Rio Grande do Sul foi a Deutscher Turnverein (Sociedade Alemã de Ginástica), fundada em 1867, na cidade de Porto Alegre. No entanto, é a partir dos momentos finais da década de 1870 e início da década de 1880 que se percebe a forte ascensão econômica de grupos alemães na indústria e no comércio na capital do Estado, um centro colonial. Portanto, a constituição de associações esportivas foi decorrente da rápida ascensão econômica dos alemães, em Porto Alegre, que também mantinham comunicação com a Alemanha, por meio de jornais em alemão, revistas e livros enviados pelos parentes alemães, e, ainda, visitas de instrutores de ginástica e de outros esportes nos clubes esportivos (MAZO, 2004).

O método de ginástica alemão (Turn) foi a primeira prática registrada pelos teuto-brasileiros nas suas associações e que emergiu em Porto Alegre. Logo depois, foi organizado o primeiro estande de tiro do Rio Grande do Sul, em 1869, quando a Turnerbund (SOGIPA) fundou o Departamento de Tiro ao Alvo, também em Porto Alegre (TESCHE, 1996, p. 63). Porém, esta prática teve maior adesão nas colônias do interior do Estado, pois as primeiras associações de tiro criadas surgiram da necessidade dos colonos de usar armas para a caça e a defesa de seus lares que se localizavam próximos à mata (OLIVEIRA, 1987). 
De acordo com Vogt (2003), na Alemanha, as associações de atiradores não tinham a finalidade esportiva. Porém, quando os alemães estabeleceram-se no Rio Grande do Sul, fundaram associações com esta finalidade, não mais obedecendo a moldes guerreiros. Contudo, este discurso não era hegemônico. Para Roche (1969), as associações de tiro do Rio Grande do Sul possuíam o intuito de preparação militar em que os instrutores, membros e alunos eram quase todos de origem germânica. Do mesmo modo, Sommer (1984) e Flores (2004) acreditam que os imigrantes organizavam-se para defender seus lares dos saques e barbáries das batalhas, formando os Selbstschutz (defesa própria); organizações estas que vieram a se transformar em associações recreativas depois das guerras.

Ainda, para entendermos como se deu a constituição das associações de tiro ao alvo, é necessário relatar, mesmo que brevemente, a história dos brummers, personagens que foram fundamentais para o surgimento das associações esportivas em geral. Em 1851, o General Sebastião de Rego Barros trouxe ao Brasil reforços militares - brummers - oriundos da Renânia (Alemanha) que lutaram na guerra contra a Dinamarca. Do total de brummers trazidos, somente 80 lutaram na guerra contra a Argentina em 1852, sendo este o principal motivo que os trouxe para o Brasil. Depois da guerra, eles foram desmobilizados e alguns retornaram para a Europa, outros faleceram. Os que permaneceram espalharam-se pelas colônias (OLIVEIRA, 1987; FLORES, 2004). Com formação acadêmica e militar, ajudaram a acelerar o progresso das colônias, atuando como professores, comerciantes, agrimensores ou diretores, como foi o caso de Lothar De La Rue que fundou Teutônia junto com Carlos Schilling (LANG, 1995, p. 18).

No Bairro da Linha Clara, em Teutônia, surgiu a primeira associação esportiva exclusivamente direcionada à prática de tiro ao alvo no ano de 1874: a Kriegerverein (Sociedade de Guerreiros). Posteriormente, esta associação tornou-se Schützenverein (Sociedade dos Atiradores) de Linha Clara, em 1910 (LANG, 1995, p.47). Esta associação esportiva foi fundada por ex-combatentes alemães das guerras contra a Áustria e a Dinamarca, segundo Magedanz (2004, p. 28), que podem ter sido brummers que permaneceram no Rio Grande do Sul no período de colonização de Teutônia, já que estes também vieram da região da Renânia na Alemanha.

Infelizmente, o acervo dessa associação esportiva foi perdido na época em que ocorreu o período político conhecido como Estado No- 
vo (1937-1945), no Brasil, e a Segunda Guerra Mundial (1939-1945), em cenário mundial, sendo difícil afirmar, com clareza, como foi criada, pois sua fundação se deu há mais de um século, não havendo nenhuma memória viva de sua história. No entanto, a manutenção dos costumes germânicos até a atualidade faz da Schützenverein de Teutônia uma das mais importantes associações esportivas do Vale do Taquari, região central do Rio Grande do Sul.

Ainda no século XIX, é possível apontarmos a prática do bolão (Kegelspiel) emergida nas casas comerciais (armazéns) da época. De acordo com Jesus (2001, p. 3), o bolão é praticado desde o início da colonização no Rio Grande do Sul e sempre mencionado como um esporte característico dos teuto-brasileiros. Becker (1987, p. 49) salienta que, apenas no início do século XIX, o referido esporte foi reconhecido na Alemanha, sendo que possui três divisões, de acordo com a cronologia do seu surgimento: as Kegelbahnen (canchas de bolão), os Kegelgruppen (grupos de bolão) e os Kegelvereine (clubes de bolão).

Primeiramente, essa prática esportiva foi desenvolvida nas canchas de bolão construídas pelos proprietários de armazéns comerciais que visavam o lucro com a venda de produtos para os praticantes. É importante destacar que foi deste modo se desenvolveu o bolão em Teutônia. Como afirma Becker (1987, p. 52), no ano de 1875 havia duas canchas de bolão em Teutônia, ambas instaladas em casas comerciais. Além destas, várias canchas foram instaladas nas demais casas comerciais de Teutônia a partir desta data, já que esta prática começava a adquirir muitos adeptos.

Num segundo momento, a partir da década de 1880, Becker (1987, p. 58) destaca o surgimento dos grupos de bolão. O grupo mais antigo do Rio Grande do Sul é o Separat, fundado em 1883 e filiado à Sociedade Orfeu, de São Leopoldo. Nesse quadro, Kreling (1984, p. 58) destaca o mais antigo grupo feminino Grupo de Bolão Violeta Arcoíris, da Associação Leopoldina Juvenil de Porto Alegre, fundado em 1914.

Os sócios praticantes do bolão reivindicavam a construção de canchas apropriadas para a prática nos clubes. No entanto, por inúmeras vezes, tais clubes negavam o empreendimento das instalações requeridas, pois queriam priorizar a prática principal definida na fundação do clube (BECKER, 1987). Entretanto, a Schützenverein de Teutônia, por exemplo, possuía uma cancha até o ano de 1925 (MAGEDANZ, 2004, p. 13), porém, devido à perda do acervo desta associação, não há re- 
gistro da data de inauguração, nem mesmo do nome de grupos que ali jogavam.

O bolão cresceu e se tornou popular somente a partir da década de 1920, tendo seu ponto alto de 1920 a 1937 . Vários grupos foram formados e mantiveram suas canchas em sociedades e ainda nas casas comerciais. Porém, poucas sociedades registraram o ano de fundação destes grupos. De acordo com Schierholt (2002, p. 333), há registros da fundação do Club Unicum de Bolão em 25 de dezembro de 1921, em Estrela. Entretanto, este foi um dos únicos clubes específicos deste esporte fundado nesta região.

Nesse contexto, antes mesmo do surgimento dos grupos e sociedades de bolão, o turfe e a ginástica estavam sendo implantados no grande centro da Colônia: Estrela. O turfe surgiu primeiro, com a construção do Prado da Vila de Estrela, inaugurado no dia 24 de dezembro de 1887, na chácara de Felisberto Fagundes Mena Barreto ${ }^{10}$. Nos estatutos, o Prado estaria preparado para corridas de cavalo e ciclismo (HESSEL, 1983, p. 76).

No estudo de Hessel (1983, p. 76) consta que, em 1888, já havia bicicletas em Estrela e, na mesma medida, já se praticava o ciclismo; assim, o Prado e as canchas retas também foram estabelecidos como locais de prática desta atividade. Numa época em que as corridas de cavalo eram bastante apreciadas, as corridas de canchas retas somente foram constituídas, em Teutônia, anos mais tarde.

Ainda no início do século XX, outra prática esportiva tomava espaço no referido cenário esportivo: a ginástica. Tal prática é inserida na cultura esportiva de Estrela a partir da fundação da Turnverein Estrella (Sociedade Ginástica de Estrela), em 28 de maio de 1907. De acordo com Hessel (1998, p. 52), os sócios eram quase só pequenos burgueses, dentre industriais, seus funcionários mais graduados, bancários, hoteleiros, religiosos e professores. Além da parte social, o foco principal da associação esportiva era a prática de ginástica, além do atletismo e de outros esportes e, na mesma medida, promoviam eventos sociais, culturais e de lazer.

A associação de ginástica mais antiga do Rio Grande do Sul foi a Sociedade de Ginástica (Gymnastikverein) que iniciou suas atividades

10-Felisberto Fagundes Mena Barreto era filho de Antônio Vítor de Sampaio Mena Barreto, fundador de Estrela, Coronel da Guarda Nacional e proprietário da empresa de navegação Vapor Estrela (SCHIERHOLT, 2002). 
no dia 6 de novembro de 1867, denominada de Deutscher Turnverein por Tesche (1996, p.63). Esta associação esportiva, junto com o Clube de Ginástica (Gymnastikklub) de 1887, resultou na criação da Turnerbund (SOGIPA) em 11 de abril de 1892 (MAZO; REPPOLD FILHO, 2005 , p. 87). Esta era a principal associação esportiva e social da elite teuto-brasileira de Porto Alegre e foi uma sociedade de expressivo trabalho em prol da germanidade (SILVA, 2006).

Desde 1896, eram organizadas competições oficiais de ginástica de solo e aparelhos, dirigidos pela Liga de Ginástica (Turnerschaft), criada em 1895. Esta Liga, por sua vez, realizava os Gauturnfeste (festivais regionais de ginástica) todos os anos no qual todas as associações de ginástica gaúchas participavam com seus atletas. O primeiro Festival de Ginástica que se tem conhecimento foi realizado em Porto Alegre, em abril de 1896. As provas esportivas eram acompanhadas por rituais de abertura, com desfile de bandeiras, entoação de hinos, tudo em língua alemã, demonstrando publicamente a germanidade dos teuto-brasileiros (TESCHE, 1996).

As sociedades de ginástica, por volta da década de 1920, incluíram vários esportes modernos, como o basquetebol, o voleibol e o futebol. Na SOGIPA, o basquetebol e o voleibol foram introduzidos em 1926. Em contrapartida, a Sociedade Ginástica Estrela constituiu suas equipes na década seguinte. Ainda na década de 1920, surge o Grêmio Esportivo Estrelense, fundado em 10 de junho de 1921, sendo este o primeiro clube estrelense registrado por Schierholt (2002, p. 319). No mesmo ano, surge o Sport Club Oriental em 23 de outubro. Neste período, as equipes eram organizadas por empresas, grupos ou bairros, e, com este intuito, outros clubes futebolísticos surgiriam nas cidades de Teutônia e Estrela.

Inicialmente, a equipe Basquetball Estrela da SOGES foi um grupo criado para prática recreativa. Schierholt $(2002$, p. 333) atenta aos registros de uma partida contra o time de basquetebol da Sociedade Ginástica de Santa Cruz do Sul, em 23 de janeiro de 1933. Neste mesmo ano, a equipe de basquete da SOGIPA veio à Estrela enfrentar a equipe da SOGES. A finalidade desta excursão foi de paraninfar a nova equipe e a primeira quadra da região do Vale do Taquari deste esporte (TESCHE, 1996, p. 67). Neste mesmo ano, no dia 2 de abril, foi inaugurada a quadra do Grêmio Esportivo Estrelense (SCHIERHOLT, 2002, p. 333).

Esportes menos expressivos em Teutônia também foram surgindo e 
oportunizando um maior número de práticas esportivas na colônia. Muito antes da fundação do Tênis Clube Estrela, em 21 de abril de 1933, já se praticava o tênis, porém sem vínculo associativo. Além do tênis, no Rio Taquari já se fazia presente a prática da natação, remo e canoagem. A primeira regata ocorreu no dia 20 fevereiro de 1932, porém todos os atletas que competiam não possuíam representação de clube (SCHIERHOLT, 2002, p. 329).

A década de 1930 foi o período em que os esportes coletivos tiveram sua maior expressividade na região do Vale do Taquari. Contudo, um destes esportes possui uma peculiaridade referente ao seu surgimento no Rio Grande do Sul. Este esporte foi o futebol, prática esportiva que surgiu, de acordo com Jesus (2001, p. 5), em 19 de julho de 1900, na cidade de Rio Grande, com o Sport Club Rio Grande e, logo depois, em Porto Alegre, surge o Grêmio Foot Ball Porto Alegrense em 15 de setembro de 1903. Mesmo com estas grandes equipes compondo o cenário do associativismo esportivo no Rio Grande do Sul, o futebol somente se tornou popular por volta da década de 1930 (MAZO; REPPOLD FILHO, 2005, p. 87).

Schierholt (2002, p. 321) relata o surgimento do Estrela Futebol Clube em 17 de novembro de 1931. Na mesma década, Hessel (1983, p. 77) relata a fundação da Liga de Futebol do Alto Taquari, que envolveu os municípios de Estrela (Teutônia), Corvo, Roca Sales, Muçum, Encantado, Arroio do Meio e Lajeado.

No interior da Colônia Teutônia/Estrela, os times de futebol de cada Picada eram extremamente bairristas, sendo que os jogadores sabiam se diferenciar acerca da procedência de cada localidade, portanto não podiam morar em uma Picada e jogar no time de outra.

Os clubes futebolísticos que surgiram entre as décadas de 1930 e 1940 consagraram-se como os maiores, permanecendo até hoje. O Grêmio Esportivo Canabarrense, do Bairro Canabarro, foi um dos primeiros, fundado em 1931, sendo que, mais tarde, veio a se tornar Sociedade Esportiva e Recreativa Canabarrense, possuindo outras práticas como o voleibol e o bolão (KILPP, 2008, p. 48).

A partir dessa equipe, surgem os times de futebol da Sociedade Esportiva e Recreativa Gaúcho, do Bairro Teutônia, da Associação Cultural e Recreativa Boa Vista, do Bairro Boa Vista, e o Flamengo Futebol Clube, da atual Westfália, fundado no dia 24 de junho de 1941. Neste mesmo período, junto com a prática do futebol, as corridas de cavalo em cancha reta tiveram seu auge. Algumas das canchas 
de Teutônia estavam localizadas na Linha Hermann, no Bairro Teutônia, na Linha Clara (atual Hípica Linha Clara) e na Linha Schmidt (KILPP, 2008).

Neste cenário esportivo, as equipes de futebol faziam torneios de final de semana, assim como os grupos de bolão, a Shützenverein e as corridas de cancha reta, de maneira que as tradições e costumes alemães se mostravam presentes, não só pela tradição esportiva deste grupo étnico, como também por meio das comemorações após os torneios. Ou seja, mesmo que o futebol tenha se tornado uma prática tomada como nacional, as comemorações, música e costumes alemães continuavam presentes, assim como nos esportes tradicionais como o bolão e o tiro ao alvo.

\section{Considerações finais}

A emergência do associativismo esportivo em Teutônia ocorreu no quarto final do século XIX, num contexto criado por uma sucessão de guerras, principalmente fronteiriças, que reascendeu os conhecimentos militares dos imigrantes alemães, moradores das regiões inóspitas que sofriam constantes incursões. Este contexto possibilitou a agremiação de um grupo de brummers, que tinham uma formação acadêmica e militar qualificada, criando a primeira associação esportiva para a prática do Tiro ao Alvo, em 1874, modalidade na qual a maior parte os imigrantes já possuía contato, tanto homens, quanto mulheres.

Passado o momento belicoso, essas associações criadas com o intuito militar e de proteção tornaram-se recreativas, mas mantiveram os costumes alemães, preservando a germanidade.

O rumo da Colônia de Teutônia foi este: uma associação esportiva que treinava ações belicosas, fé na religião protestante e um isolamento geográfico que possibilitou uma coesão familiar e étnica muito forte. Estes três aspectos foram de fundamental importância para estes imigrantes fortalecerem a germanidade, tanto que as tradições e costumes dessa região são mantidos até hoje, persistindo mesmo nas guerras e formando uma história de várias gerações.

Com a germanidade reforçada, as práticas esportivas que em Teutônia se desenvolveram foram as mais tradicionais dos alemães e europeus. Além do Tiro ao Alvo, que era uma prática bastante interiorana, o Bolão também tinha muita aceitação. A partir de 1875, havia canchas em várias casas comerciais. Desta forma, esta prática cresceu, 
passou por gerações e permanece até os dias atuais.

Outra prática esportiva foi o Futebol, que teve seu auge a partir dos anos 1930, período pós-guerra. Isto se deve à posição contrária do Brasil nestas investidas em relação à Alemanha. Com a perseguição à germanidade e a proibição do uso de língua alemã e de seus costumes, os esportes tradicionais alemães perderam a força, dando lugar para o surgimento de outros; e foi aí que surgiu o Futebol, o Voleibol e o Basquetebol. Estes esportes foram trazidos por outros grupos étnicos, porém, o alemão, mesmo não contribuindo com o associativismo exclusivamente, deste participava, ainda que indiretamente.

A Colônia de Estrela era a região mais próspera do município, onde o comércio e a indústria prosperaram, devido ao Porto para o comércio e transporte fluvial. Essa região aproxima-se da conformação urbana de Porto Alegre. Assim, foi neste centro colonial que surgiu a Sociedade Ginástica de Estrela, em 1907. Além desta prática, assim como em Porto Alegre, surgiram as primeiras bicicletas usadas na prática do ciclismo no Prado de Estrela, já que estes velocípedes eram caros e vinham da Europa. O Prado, de 1887, também era característico de centros urbanos, pois no interior eram realizadas as corridas em cancha reta.

As associações de Tiro ao Alvo foram as primeiras a surgirem, no final do século XIX, seguidas dos grupos de Bolão, corridas de cavalo no Prado Estrelense e o Turnverein de Estrela no início do século XX. O quadro se completa com as práticas do Futebol, Voleibol, Basquetebol, Ciclismo, Tênis, Natação, Remo e Canoagem, emergentes da metade do século XX em diante.

Há uma ligação muito forte do esporte com a ascensão econômica da colônia. Isto é claramente observado nos tipos de práticas que surgem nas localidades, como por exemplo: o Turn em Estrela, centro econômico e comercial da região, e o Tiro ao Alvo, prática interiorana. Estas práticas que surgiram nos centros coloniais também eram as que necessitavam de mais incentivos econômicos, além de locais adequados para a prática. Já as práticas esportivas do interior das colônias necessitavam de materiais mais comuns entre os imigrantes, como as armas da Sociedade de Tiro.

Por fim, é importante deixar claro que a atuação alemã na construção das práticas esportivas no Rio Grande do Sul é extremamente importante, seja com seus símbolos, costumes e tradições, seja com a persistência e a capacidade social dos imigrantes. Isto tudo devido às 
suas peripécias ao chegarem ao Rio Grande do Sul, seus esforços e realizações, tanto para a Colônia quanto para a nova nação, que cresceu e se desenvolveu política, econômica e socialmente.

\section{A historical look at the appearance of first sports clubs in Teutônia city at the state of Rio Grande do Sul}

We aimed at identifying how was organised the first sports associations in Teutonia city at the State of Rio Grande do Sul (Brazil). In order to do so, we used historical documents on the clubs. A context of war enabled a group of German immigrants creating the first sports club to practise shooting, and other traditional practices were included into associations - e.g. bowling, gymnastic, track and field, and cycling. When the territorial wars finished, clubs kept the German custom, but the German immigrants were chased during the Second World War and the Estado Novo (New State) in Brazil. It impacted on clubs, weakening the traditional German sports and including other practices - e.g. football, volleyball and basketball.

Keywords: Clubs - History of Sport - Ethnic identities

Una mirada histórica a la aparición de los primeros clubes deportivos en la ciudad de Teutonia en Rio Grande do Sul

El estudio tuvo como objetivos identificar cómo se organizó las primeras asociaciones deportivas en la ciudad de Teutonia en Rio Grande do Sul. Con este fin, hemos utilizado los documentos históricos sobre los clubes. Un contexto bélico permitió a un grupo de inmigrantes alemanes crear el primer club deportivo para la práctica de tiro y desde entonces otras prácticas tradicionales que se han introducido en la asociación: "bolão", gimnasia, atletismo y ciclismo. Pasadas las guerras de posiciones, los clubes de manteneran las costumbres alemanas, pero com La Segunda Guerra Mundial y el Estado Novo en el Brasil hubo una persecución de los inmigrantes alemanes que refleja los clubes con el debilitamiento de los deportes tradicionales de Alemania y la inclusión de otras prácticas como el fútbol, voleibol y baloncesto.

Palabras clave: Clubs - Historia del Deporte, Identidades Étnicas

\section{Referências}

BECKER, K. O esporte do bolão no RS. In: IV SIMPÓSIO DE HISTÓRIA DA IMIGRAÇÃO E COLONIZAÇÃO ALEMÃ NO RS. Anais... São Leopoldo: Gráfica UNISINOS, 1987. p. 249 - 264.

BURKE, P. O que é história cultural? Rio de Janeiro: Jorge Zahar, 2005.

FLORES, H. História da imigração alemã no Rio Grande do Sul. 
Porto Alegre: EST Editora, 2004.

GERTZ, R. O integralismo na zona colonial alemã. In: LANDO, A.; BARROS, E. (org). Rio Grande do Sul: imigração \& colonização. Porto Alegre: Mercado Aberto, 1980. p. 9-46.

HESSEL, L. Apreciações raciais e sociais no Alto Taquari (1910 1930). In: FISCHER, Luís, GERTZ, René (org). Nós, os teuto-gaúchos. Porto Alegre: Editora UFRGS, 1998. p 51-55.

. Município de Estrela. Porto Alegre: Editora UFRGS, 1983.

JESUS, G. de. Imigrantes desportistas: os alemães no sul do Brasil. Revista Eletrônica de Geografia y Ciências Sociales, Barcelona, v. 5, n. 94, índice 108, ago. 2001.

KILPP, C. E. Kriegerverein: a constituição da Sociedade de Guerreiros e das primeiras associações esportivas de Teutônia/Estrela (18741950). 2008. 66f. Monografia (Licenciatura em Educação Física) Curso de Educação Física, Universidade Federal do Rio Grande do Sul, Porto Alegre, 2008.

KRELING, H. O bolão: o esporte nas colônias alemãs do RS. Porto Alegre: Martins Livreiro, 1984.

LANDO, A.; BARROS, E. Capitalismo e colonização: os alemães no RS. In: (org). Rio Grande do Sul: imigração \& colonização. Porto Alegre: Mercado Aberto, 1980, p. 09-46.

LANG, G. A colonização westfaliana. In: FISCHER, L.; GERTZ, R. (orgs). Nós, os teuto-gaúchos. Porto Alegre: Editora UFRGS, 1998. p 15-20.

. Colônia Teutônia: história e crônica (1898 - 1908). Novo Hamburgo: Gráfica Sinodal, 1995.

MAGEDANZ, A. Linha Clara, Teutônia e os 180 anos da imigração alemã no RS. Teutônia: Edição do autor, 2004.

MAZO, J.; REPPOLD FILHO, A. (orgs). Atlas do esporte no Rio Grande do Sul. Porto Alegre: CREF2RS, 2005. 
MAZO, J. A emergência e a expansão do associativismo desportivo em Porto Alegre - Brasil (1867-1945): espaço de representação da identidade cultural teuto-brasileira. 2003. 396 f. Tese (Doutorado em Ciências do Desporto) - Universidade do Porto (UP), Porto, 2004.

MOURE, T. A inserção da economia imigrante na economia gaúcha. In: LANDO, A.; BARROS, E. (orgs). Rio Grande do Sul: imigração \& colonização. Porto Alegre: Mercado Aberto, 1980. p. 91-113.

OLIVEIRA, P. A imigração alemã e a introdução do punhobol no RS. 1987. 251 f. Dissertação (Mestrado em Ciências do Movimento) Faculdade de Educação Física, Universidade Federal de Santa Maria, Santa Maria, 1987.

PESAVENTO, S. História \& história cultural. Belo Horizonte: Autêntica, 2004.

ROCHE, J. A colonização alemã e o Rio Grande do Sul. Porto Alegre: Globo, 1969.

SCHIERHOLT, J. A. Estrela: ontem e hoje. Lajeado: Edição do autor, 2002.

SILVA, H. Entre o amor ao Brasil e ao modo de ser alemão. São Leopoldo: Oikos, 2006.

SOMMER, A. Reminiscências da colônia Teutônia - Estrela: décadas de 20 e 30. São Leopoldo: Rotermund, 1984.

TESCHE, L. A prática do turnen entre imigrantes alemães e seus descendentes no RS: 1867-1942. Ijuí: Editora UNIJUÍ, 1996.

VOGT, O. Germanismo e nacionalização em Santa Cruz do Sul, RS. Revista Ágora: Migração e Identidade. Santa Cruz do Sul, v. 7, n. 2. p. 49-92, 2003.

Recebido em: 09/10/2009

Revisado em: 28/10/2009

Aprovado em: 12/02/2010

Endereço para correspondência

janmazo@terra.com.br 
Janice Zarpellon Mazo

Universidade Federal do Rio Grande do Sul, Escola Superior de Educação Física. Rua Felizardo 750

Jardim Botânico

90690-200 - Porto Alegre, RS - Brasil 